\title{
Redox flow batteries for energy storage: their promise, achievements and challenges
}

\author{
Luis F. Arenas, Carlos Ponce de León*, Frank C. Walsh
}

\author{
Electrochemical Engineering Laboratory, Energy Technology Research Group, Faculty of \\ Engineering and Physical Sciences, University of Southampton, Highfield, Southampton, SO17 \\ 1BJ, United Kingdom \\ * Corresponding author: Ponce de León, Carlos (capla@soton.ac.uk)
}

\begin{abstract}
Redox flow batteries continue to be developed for utility-scale energy storage applications. Progress on standardisation, safety and recycling regulations as well as financing has helped to improve their commercialisation. The technical progress of redox flow batteries has not considered adequately the significance of electrolyte flow velocity, mass transfer and plug flow reactor modelling, despite steps in the right direction. 3D simulations of fluid flow, pressure drop, current distribution and mechanical resistance using commercial software are becoming more common, but satisfactory validation by experiments is still unusual. The majority of research tends to report short term studies on small electrodes, often in poorly defined flow channels; long term evaluation of electrode and membrane durability on a pilot scale is needed. Digital imaging of electrode structure using X-ray computed tomography is increasingly being used. Much activity is directed to organic and non-aqueous systems. However, scale-up and high, sustained charge capacity using electrolytes of moderate cost which are environmentally acceptable to source, store, transport and handle require considerable attention. Recommendations for future work are discussed.
\end{abstract}

Keywords: electrochemical engineering, energy storage, mathematical modelling, redox flow batteries, state of charge, vanadium

(2,400 words; 4 figures; 97 references, 14 of them commented on) 


\section{Introduction}

The deployment of redox flow batteries (RFBs) has grown steadily due to their versatility, increasing standardisation and recent grid-level energy storage installations [1]. In contrast to conventional batteries, RFBs can provide multiple service functions, such as peak shaving and sub-second response for frequency and voltage regulation, for either wind or solar power generation and the power grid. Relevantly, they are now considered a safer alternative to Li-ion stationary systems for indoor use in buildings [2]. Since devices complying with local legislations on fire safety and electrolyte management will have competitive advantages, standardisation of RFBs has been progressed via the International Electrotechnical Commission [3], as an addition to updated grid storage standards [4].

The large-scale deployment of RFBs in a multi-device energy market with many service providers has been hindered by the perception that the technology is still in an early stage of development and by the relatively high capital costs due to electrolytes (e.g. vanadium) and ion exchange membranes. However, market conditions have become more favourable for RFB manufacturers. The rising cost of wind power curtailment has incentivised heavy investment in China [5], while electrolyte leasing models have relieved the impact of vanadium costs [6]. Moreover, the price of cobalt in Li-ion cell cathodes has more than doubled since 2016 [7], due to the 'high-risk' status of its supply chain [8]. Work continues on the commercialisation of other RFBs systems, mainly zinc-bromine [9] and the search for feasible organic chemistries continues [10]. The prospective success of such systems could overcome present limitations. While the principles of this technology are well-known, the path to scale-up and development has often been unclear to researchers [11]. The full potential of RFBs has yet to be realised. Progress is currently 
hindered by the scarcity of electrochemical engineering studies on reaction environment and cell design and their relation to performance and efficiency.

\section{Mass transfer in redox flow batteries}

RFBs consist on arrays of electrochemical flow reactors [11]. Reactant conversion, cycling performance and energy efficiency are related to the global mass transfer coefficient, $k_{m}$, due to the mixed reaction control at each electrode, which depends on the supply of reactant. The electrochemical performance is always tied to the total active electrode surface area, $A$, which can be difficult to determine and can even be timedependent (mainly during the initial commissioning). A simple method to characterise electrochemical cells under full mass transfer control is to obtain the performance factor $k_{m} A$, typically for a diluted model redox couple. In porous electrodes, the surface area per unit volume, $A_{e}$, can be considered, the factor thus becoming $k_{m} A_{e}$. The fundamental relationship to the limiting current, $I_{L}$, is:

$$
k_{m} A_{e}=\frac{I_{L}}{z F c V_{e}}
$$

where $\mathrm{z}$ is the electron stoichiometry, $F$ is the Faraday constant, $c$ is concentration and $V_{e}$ is the volume of the electrode. The performance factor can predict the rate and fractional conversion (maximum rate of the state of charge, SOC) during scale-up using either analytical or numerical modelling approaches. Empirical power laws are also instructive, e.g., $k_{m} A_{e}$ as a function of mean electrolyte flow rate, $v$, as well as dimensionless correlations involving Sherwood, Péclet, and Schmidt numbers, which facilitate scale-up and comparison among different cells. Further work can extend the implementation of the fundamental expression when considering significant single-pass conversion, concentrated electrolytes or parasitic reactions. 
A classical route to determine $k_{m} A_{e}$ is the measurement of limiting currents assuming a steady state, as applied recently to electrode materials within rectangular channel flowthrough cells for cerium-based RFBs [12], and borohydride fuel cells [13]. This factor can be related to the pressure drop, $\Delta P$, over a range of $v$ values, as shown in Fig. 1, as an indication of scale-up feasibility [14]. Each correlation in the plot corresponds to the behaviour of a different electrode material in a particular cell compared to the FM01-LC electrolyser. A modified expression relating $k_{m} A_{e}$ to a limiting current has been experimentally validated for the case of carbon felt electrodes using the $\mathrm{Fe}^{2+} / \mathrm{Fe}^{3+}$ redox couple in a diluted electrolyte [15]. Meanwhile, values for $k m$ at the pore level have been obtained in a similar method using vanadium electrolyte in a laboratory RFB [16].

A way to increase mass transfer is the use of a zero-gap electrode architecture with flow field designs $[17,18,19]$, which have been widely used in gaseous fuel cells. This strategy has already demonstrated significant improvements to the power density of vanadium cells and stacks [20], reaching values up to $2588 \mathrm{~mW} \mathrm{~cm}^{-2}$ [19]. (Challenges to their implementation are discussed in a following section.) The mass transfer properties of cells having flow fields, however, have received insufficient attention. One of the first works towards establishing $k_{m}$ for these features was carried out with vanadium electrolyte and carbon felt via the limiting current method [16]. As shown in Fig. 2, $k_{m} A_{e}$ was later determined for different flow field designs in a single-electrolyte flow cell using carbon paper as a function of $v$ at the flow channels using a one-dimensional model [21]; a step towards reporting normalised flow in interdigitated cells. Dimensionless performance parameters showed that interdigitated flow fields outperformed other designs. In a 
following work [22], the same group evaluated the effect of flow rate and electrolyte viscosity on $k_{m} A_{e}$, limiting current and pressure drop. An expression for $k_{m}$ considering the viscosity of the electrolyte was proposed:

$$
S h \equiv \frac{k_{m} d_{f}}{D}=\frac{D a \cdot \kappa_{e f f} \mathrm{RT} d_{f}}{\theta F^{2} c A_{e} S^{2} D}
$$

Where $S h$ is the Sherwood number, $d_{f}$ is the fibre diameter, $D$ is the diffusion coefficient, $D a$ is the so-called Damköhler number, $\kappa_{\text {eff }}$ is the effective solution conductivity, $R$ is the universal gas constant, $T$ is temperature and $S$ is the electrode thickness. Notably, the exchange current density to limiting current density ratio, $\theta$, an often-unappreciated ratio for electrode processes, is contained in the equation and was plotted as a function of $v$.

The pressure drop over flow fields in cells $[23,24,25]$, has yet to be directly correlated to mass transfer. In some cases (e.g. certain laboratory-scale cell suppliers) flow field designs for proton-exchange fuel cells (PEMFCs) have simply been moved across to RFBs with insufficient thought. PEMFCs employ gases, while most RFBs involve liquids with much higher viscosity. Furthermore, the transport properties of the flow fields depend on their size and shape and do not scale-up linearly [24]. Thus, efforts in this promising area should be directed towards studies which can be readily scaled-up or represent full-size cells, e.g. [26].

Both the local mass transfer at fibre level and the global mass transfer coefficient in utility-scale electrodes experiencing non-homogeneous porous fluid flow can be simulated. For instance, by digitising their geometry from X-ray CT scans, mass transfer coefficients and dimensionless correlations have been calculated for carbon felts using 
the Lattice Boltzmann method (LBM) [27,28]. This allowed correlations to be established at low Reynolds numbers [27], along global dispersion and reaction rate coefficients [28]. The local mass transfer at felts within interdigitated flow fields has also been determined by numerical simulations [29,30], although those for flow-through rectangular channel electrodes have not received adequate attention. Contrary to the previous examples, the models discussed in the following section emphasise other parameters and incorporate mass transfer rates from reported correlations. It should be noted that any employed correlations must be strictly valid for the model assumptions.

\section{Mathematical modelling}

In general, the modelling of RFBs is accompanied by insufficient experimental validation and the introduction of arbitrary fitting factors. Numerous examples exist of practical zero-, one- and two- dimensional models of cell potential over charge-discharge cycles. However, given the widespread availability of computational power, opportunities for improvement can be found in the replacement of simplified assumptions for representations of the physical geometry of, and reaction environment within, the device, e.g., dispersed plug flow reactor (PFR) models applied to three-dimensional electrodes. Models considering PFRs are scarce [31,32], despite flow reactors generally following this behaviour. There is also a tendency to omit reference electrodes from each half-cell, ignore the value of a redox probe in the reservoirs and neglect the classical model of a PFR with batch recirculation to a fixed volume electrolyte reservoir (for mass transfercontrolled cases, which are useful for reactor design and characterisation). 
Zero-dimensional models for flow rate optimisation have been recently considered [33]. For instance, an iterative model has been used to determine a variable flow factor as a function of SOC and coupled to pressure drop [34]. The model follows a quasi-plug flow reactor as a compromise with computational efficiency [32]. The concentration overpotential in a commercial vanadium RFB was later modelled using a zerodimensional approach [35]. Since this type of model cannot consider the porous area of the electrode, a scaling factor was applied to the geometrical electrodes in order to produce practical results. Other RFBs models develop control algorithms, e.g., extended Kalman filter (EKF) for capacity monitoring [36], SOC estimation considering the capacity fading [37], and time flow control for charging using solar cells [38] or wind power [39].

Techno-economic feasibility models have been recently reviewed [40]; most of them centre on capital cost, stressing the significant role of vanadium reactants, and revealing wide variability in the assumed prices of membranes and ancillary equipment. Recently, two models for grid-level energy storage, one in Germany [41], and the other in the USA [42], concluded that RFB investment costs should be reduced by $20-30 \%$, in order to remain competitive. Notably, a model for the implementation of large-area electrodes has estimated potential cost reductions of about $25 \%$ [43], while new models could establish up-to-date cost and financing targets by taking into account new electrolyte leasing schemes [6]. Regarding lobbying opportunities, a case study has pointed out the need for flexible tariffs in order to maximise storage value [44]. The environmental life cycle assessment of vanadium systems has been carried out [45], highlighting their improved recyclability compared to $\mathrm{Li}$-ion batteries. 
Numerical, three-dimensional 'multiphysics' simulations can evaluate the fluid flow distribution, mass transfer-driven current density, pressure drop and shunt currents over the whole electrode and cell geometries while describing charge-discharge performance. Such models have permitted to analyse the efficiency of different stack configurations [46] and cell designs [47]. Other models have focused on specific parameters, such as flow rate and pressure trade-offs $[48,49,50]$, or electrode polarisation and contact resistance due to felt compression [51]. Recent mechanical models of cell stacks [52] should aid reliable manufacture and durability.

A variety of cell designs has been studied in terms on CFD fluid flow and pressure drop calculations, including flow-through cells [53], as well as serpentine and interdigitated flow fields $[24,49,54,55]$. Interdigitated flow fields can be more effective in ensuring high mass transfer. Necessary optimisation studies of the dimensions of flow field channel depth and width, in relation to the bipolar plate 'rib' area, are available for bromine [29], and vanadium cells [30]. Normalised, validated scale-up for flow field designs provides an important research opportunity. A marked limitation of these studies is that they consider cells under $10 \mathrm{~cm}^{2}$ electrode area, whereas utility-scale cells might involve 2,000 $\mathrm{cm}^{2}$ electrodes. As mentioned before, current correlations applied to flow fields scale-up in a non-linear manner.

Current and potential distribution are the result of the combined effect of electrical resistances, reaction kinetics, mass transfer and electrode geometry. A validated model for such phenomena in interdigitated flow fields has been developed [56], considering non-uniform compression of the felt [57]. Experimental current distribution studies have 
shown non-homogeneous patterns in some interdigitated flow fields [58], a concern that must be solved for successful scale-up. Primary, secondary, tertiary or actual current distributions, as well as the method for coupling mass transfer to the tertiary distribution are missing from these studies. On the other hand, validation of potential distribution during mass transfer limiting conditions has been achieved using platinum probes [59].

Numerical simulations have addressed shunt currents in cell stacks. For instance, in conjunction to electrode overpotentials and manifold ionic current [60], and in terms of electrochemical reaction rate distribution [61]. As shown in Fig. 3, the latter study highlights that localised corrosion due to opposite, parasitic electrode reactions can take place near electrolyte manifolds if the stack does not incorporate anti-shunt currents features. The trade-off of shunt current distribution has also been estimated for different stack configurations [46]. In previous studies, scenarios that allow shunt currents have been deliberately analysed. Effective preventing measures must also be modelled. Equivalent circuits of shunt currents in utility-scale devices continue to be an effective tool to predict losses and optimise the number of cells [62].

\section{Manufacturing, materials and utility-scale research needs}

The manufacture of RFBs aims to achieve reliability over extended life-time, dimensional tolerances for scale-up and cost-effective mass production. Few works have focused on the longevity of materials. For instance, degradation of proposed polypropylene [63] and sulfonated membranes [64], or aging of carbon felt [65,66,67]. Regarding manufacturing tolerances, stacks under compression are now being evaluated using X-ray computed tomography (CT) [68], revealing possible deformation after assembly or over time. This 
approach could be used to validate mechanical stress distribution models [52]. CT is also being employed to study the effect of compression on carbon felt properties [27], and to determine the surface area of porous electrodes (but only after calibration and validation of the methodology) [69]. In relation to materials research, limited attention has been given to the advantages and limitations of composite membranes [70,71] and to the homogeneity of carbon felt, which is important in large cells.

Considerations such as electrolyte fluid flow, mass transfer, pressure drop, active electrode surface area and current distribution at relatively large electrodes become important at a realistic scale [11]. Hence the need to obtain data from larger cells which experience edge and manifold effects, flow maldistribution, and shunt currents, all under power conditioning regimes $[35,72,73,74,75]$. If needed, practical characterisations of such systems can be carried out in a cost-effective manner. This has been demonstrated for a utility-scale vanadium RFB, shown in Fig. 4, which was studied in energy efficiency terms (accounting for convertor efficiency, parasitic reactions and pumping demands) by using accurate transducers and instrumentation.

Meanwhile, the development of extended-area, flexible $2.5 \mathrm{~m}^{2}$ electrodes based on welded carbon felt-sheets has been announced [76]. Mathematical models have shown that such an intensive scale-up could bring down RFBs capital costs significantly [43]. The design of large cells could benefit from experience in chlor-alkali stacks, although it will be essential to study and report the effects of flow dispersion, pump energy demand and concentration gradients on their efficiency. Regarding the development of bipolar plates, the requirements for the manufacture of flow fields should be discussed, together 
with their impact on the cost and complexity of stacks. These features are typically made by Computer Numerical Control (CNC) manufacturing, but it is not clear if they could be produced by alternative methods, e.g., injection moulding. The possibility of blockage by fibre sludge in large cells over extended cycling should be considered and prevented. Additive manufacturing to build 3D objects has also been consider to design electrochemical cells with characteristics that would not be possible to realise by CNC and to created rapid prototypes [11].

Research should also pay more attention to the experimental characterisation of pressure drop $[77,14,78]$, in special due to the urgent need for validation of CFD models. As mentioned previously, simulations have frequently neglected comparisons against experimental data. Still, the optimisation of pumping power consumption is increasingly analysed [79,77], especially for interdigitated flow fields [49,22], although intrinsically more efficient pumps have yet to be considered [80]. Pulsating flow changing its direction has been visualised in laboratory cells relying on peristaltic pumps [49]. This is the reason why pulse dampeners should be implemented to achieve continuous flow in such cells [12]. Flow visualisation can incorporate thermal imaging [49,81].

Regarding other practical issues, water transfer trough the membrane, the effect of migration and the necessary system rebalancing to recover capacity fading in vanadium RFBs are increasingly acknowledged [82,37,36,83]. However, detailed balancing procedures for large cells are practically missing from the literature. Despite the availability of many laboratory methods, reliable plant-level SOC monitoring is still needed, as commercial systems use charge integration due to the inconsistencies in 
monitoring cells after cross-mixing over many cycles. To address this, extended Kalman filters have been adopted [36,37]. Investigations continue regarding in situ current distribution and single pass SOC changes [84]. On a different matter, problems with the reproducibility of the composition and purity of vanadium electrolytes have been identified [85]. Indeed, best practice and standard procedures for the chemical analysis of vanadium electrolytes have not been agreed.

\section{Organic and other alternative chemistries}

Organic electroactive species dissolved in aqueous or non-aqueous media represent an attractive alternative to inorganic redox species. Organic molecules can be manipulated by introducing functional groups that can alter their solubility, redox potential [86], energy density [87], or choice of supporting electrolyte [88,89]. Recent review papers $[10,90]$, have highlighted the challenges for developing organic redox flow batteries which include: appropriate materials, safety, low cost, high energy density, larger electrolyte volumes, symmetrical and unsymmetrical cyclability, development of mathematical models and the design of stacks with the appropriate electrochemical engineering. Typical electrolytes for organic RFB are non-aqueous and, more recently, eutectic electrolytes [91]. Most organic chemistries are still challenged by poor stability, hygroscopicity and difficult or expensive synthesis. Work has indeed focused on the stability of redox organics [92,93], including disproportionation systems [94,95], which are interesting for having the same initial composition in both half-cells. Ongoing research should be directed towards demonstrating the reliability of organic RFBs beyond the glovebox (low oxygen, dry atmosphere), at the laboratory pilot-scale. This will require the suitability of the components and materials employed in the flow system to be scrutinised, together with the need for ancillary dry or inert gas supplies, all of which 
must be cost-effective. Of course, these complications could be avoided by finding inexpensive, stable and easy-to-handle organic redox couples and solvents.

\section{Conclusion}

Several general points may be made:

1. The majority of academic studies focus on the development of catalysts tested in small electrochemical cells. However, they are not realistic for advancing the technology of RFB; they are limited to short term laboratory experiments and, in general, the figures of merit such as mass transport, space time velocity or pressure drop suitable for scale-up, are not reported. The durability of the stack, catalyst and electrode materials still receive insufficient attention.

2. The reaction environment in many cells remains unclear, due to inadequate attention to experimental measurements on the distribution of current, potential, concentration and flow velocity; flow visualisation studies are rarely reported; on-line determination of accurate SOC is still under development.

3. Simplified computational models tend to be used, being validated in fewer cases than expected. 3D models extended the scope beyond flow dynamics into the assessment of current distribution, mechanical considerations and shunt currents.

4. The use of small electrodes and cells in poorly defined flow channels does not provide current-electrode area data which will scale-up in a linear fashion, due to maldistribution of current and flow. Examples of studies employing representative electrode sizes are found in references [96] and [26]. 
5. Many studies do not take the opportunity to incorporate reference electrodes in each half-cell, e.g. see reference 97, enabling potential distribution and cell potential components to be expressed as a function of current density for each electrode reaction.

6. Few studies of vanadium RFBs appreciate that OCP probes in the half-cell electrolyte reservoirs or flow loops can be used to monitor SOC via the solution redox potential.

7. It is poorly understood that electrolyte flow regime, channel equivalent (hydraulic) diameter, mean linear flow velocity of electrolyte and pressure drop are critical parameters characterising any RFB flow cell.

8. Regardless of the type of study, the mass transport properties of a RFB cell should be assessed as a function of mean electrolyte velocity past the electrode surface, $v$, e.g., against a diluted model redox couple. This would provide a basic quantitative indicator of their reaction environment and permit more rigorous comparisons against other experimental conditions and cell or stack designs/sizes.

9. There are very few case studies of scale-up, full size cell characterisation or plant performance during extended operation. While proprietary considerations are appreciated, this situation limits confidence in future roll out and wider deployment of the technology.

\section{Conflict of interest statement}

The authors declare that there is no conflict of interests.

\section{Acknowledgements}

LFA and CPL acknowledge the financial support of Newton Fund and Innovate UK. LFA acknowledges additional support from the RIFI of the University of Southampton and fruitful discussions with colleagues at conferences. 


\section{References and recommended reading}

Papers of particular interest, published within the period of review, have been highlighted as:

- Paper of special interest

-• Paper of outstanding interest.

[1] Office of Electricity Delivery \& Energy Reliability, Sandia National Laboratories, DOE Global Energy Storage Database, Energystorageexchange.org. https://www.energystorageexchange.org/policies (accessed December 1, 2018).

[2] Big battery boom hits another roadblock: Fire-fearing cities, Bloomberg. (2018). https://www.bloomberg.com/news/articles/2018-05-18/the-big-batteryboom-hits-another-roadblock-fire-fearing-cities (accessed November 19, 2018).

[3] International Electrotechnical Commission, IEC - TC 21 Work programme, Secondary cells and batteries, Iec.Ch. (2018).

https://www.iec.ch/dyn/www/f?p=103:23:0::::FSP_ORG_ID:1290 (accessed November 21, 2018).

[4] International Standard IEC 61427-2:2015, Secondary cells and batteries for renewable energy storage - General requirements and methods of test - Part 2: On-grid applications, 1st ed., International Electrotechnical Commission, 2015.

[5] Z.G. Yang, Is this the ultimate grid battery? IEEE Spectrum. 54 (2017) 36-41. doi:https://doi.org/10.1109/MSPEC.2017.8093799.

[6] Vanadium is the latest beneficiary of the battery craze, The Economist. (2018). https://www.economist.com/business/2018/07/21/vanadium-is-the-latestbeneficiary-of-the-battery-craze (accessed November 19, 2018).

[7] Historical cobalt prices and price chart. Investment Mine. (2018). http://www.infomine.com/investment/metal-prices/cobalt/all/ (accessed November 19, 2018).

[8] E.A. Olivetti, G. Ceder, G.G. Gaustad, X. Fu, Lithium-ion battery supply chain considerations: Analysis of potential bottlenecks in critical metals, Joule. 1 (2017) 229-243. doi:10.1016/j.joule.2017.08.019. 
[9] L.F. Arenas, A. Loh, D.P. Trudgeon, X. Li, C. Ponce de León, F.C. Walsh, The characteristics and performance of hybrid redox flow batteries with zinc negative electrodes for energy storage, Renew. Sust. Energ. Rev. 90 (2018) 992-1016. doi:10.1016/j.rser.2018.03.016.

[10] X. Wei, W. Pan, W. Duan, A. Hollas, Z. Yang, B. Li, et al., Materials and systems for organic redox flow batteries: Status and challenges, ACS Energy Lett. 2 (2017) 2187-2204. doi:10.1021/acsenergylett.7b00650.

[11] - L.F. Arenas, C. Ponce de León, F.C. Walsh, Engineering aspects of the design, construction and performance of modular redox flow batteries for energy storage, J. Energy Storage. 11 (2017) 119-153. doi:10.1016/j.est.2017.02.007.

A review summarizing general principles of flow battery technology and performance from an electrochemical engineering perspective.

[12] L.F. Arenas, C. Ponce de León, F.C. Walsh, Mass transport and active area of porous $\mathrm{Pt} / \mathrm{Ti}$ electrodes for the $\mathrm{Zn}$-Ce redox flow battery determined from limiting current measurements, Electrochim. Acta. 221 (2016) 154-166. doi:10.1016/j.electacta.2016.10.097.

[13] A.A. Abahussain, C. Ponce de León, F.C. Walsh, Mass-transfer measurements at porous 3D Pt-Ir/Ti electrodes in a direct borohydride fuel cell, J. Electrochem. Soc. 165 (2018) F198-F206. doi:10.1149/2.0751803jes.

[14] - L.F. Arenas, C. Ponce de León, F.C. Walsh, Pressure drop through platinized titanium porous electrodes for cerium-based redox flow batteries, AIChE J. 64 (2018) 1135-1146. doi:10.1002/aic.16000.

A study linking volumetric mass transfer coefficient to pressure drop as an indication of cost-benefit estimations and feasibility of scale-up.

[15] X. You, Q. Ye, P. Cheng, The dependence of mass transfer coefficient on the electrolyte velocity in carbon felt electrodes: Determination and validation, J. Electrochem. Soc. 164 (2017) E3386-E3394. doi:10.1149/2.0401711jes.

[16] Q. Xu, T.S. Zhao, Determination of the mass-transport properties of vanadium ions through the porous electrodes of vanadium redox flow batteries, Phys. Chem. Chem. Phys. 15 (2013) 10841-8. doi:10.1039/c3cp51944a.

[17] D.S. Aaron, Q. Liu, Z. Tang, G.M. Grim, A.B. Papandrew, A. Turhan, et al., Dramatic performance gains in vanadium redox flow batteries through modified 
cell architecture, J. Power Sources. 206 (2012) 450-453.

doi:10.1016/j.jpowsour.2011.12.026.

[18] X.L. Zhou, T.S. Zhao, L. An, Y.K. Zeng, L. Wei, Critical transport issues for improving the performance of aqueous redox flow batteries, J. Power Sources. 339 (2017) 1-12. doi:10.1016/j.jpowsour.2016.11.040.

[19] X. Ke, J.M. Prahl, J.I.D. Alexander, J.S. Wainright, T.A. Zawodzinski, R.F. Savinell, Rechargeable redox flow batteries: flow fields, stacks and design considerations, Chem. Soc. Rev. 41 (2018) 54-23. doi:10.1039/C8CS00072G.

[20] B.R. Chalamala, T. Soundappan, G.R. Fisher, M.R. Anstey, V.V. Viswanathan, M.L. Perry, Redox flow batteries: an engineering perspective, Proc. IEEE. 102 (2014) 976-999. doi:10.1109/JPROC.2014.2320317.

[21] - J.D. Milshtein, K.M. Tenny, J.L. Barton, J. Drake, R.M. Darling, F.R. Brushett, Quantifying mass transfer rates in redox flow batteries, J. Electrochem. Soc. 164 (2017) E3265-E3275. doi:10.1149/2.0201711jes.

Presents the product of mass transfer coefficient and volumetric electrode surface area for some interdigitated flow field designs in a symmetrical cell.

[22] •• J.L. Barton, J.D. Milshtein, J.J. Hinricher, F.R. Brushett, Quantifying the impact of viscosity on mass-transfer coefficients in redox flow batteries, J. Power Sources. 399 (2018) 133-143. doi:10.1016/j.jpowsour.2018.07.046.

Provides an explicit, separate quantification of current due to kinetic and mass transfer control of electrode reactions.

[23] R.M. Darling, M.L. Perry, The influence of electrode and channel configurations on flow battery performance, J. Electrochem. Soc. 161 (2014) A1381-A1387. doi:10.1149/2.0941409jes.

[24] E. Knudsen, P. Albertus, K.T. Cho, A.Z. Weber, A. Kojic, Flow simulation and analysis of high-power flow batteries, J. Power Sources. 299 (2015) 617-628. doi:10.1016/j.jpowsour.2015.08.041.

[25] C.R. Dennison, E. Agar, B. Akuzum, E.C. Kumbur, Enhancing mass transport in redox flow batteries by tailoring flow field and electrode design, J. Electrochem. Soc. 163 (2016) A5163-A5169. doi:10.1149/2.0231601jes.

[26] D. Reed, E. Thomsen, B. Li, W. Wang, Z. Nie, B. Koeppel, et al., Performance of a low cost interdigitated flow design on a $1 \mathrm{~kW}$ class all vanadium mixed 
acid redox flow battery, J. Power Sources. 306 (2016) 24-31.

doi:10.1016/j.jpowsour.2015.11.089.

[27] - M.D.R. Kok, R. Jervis, T.G. Tranter, M.A. Sadeghi, D.J.L. Brett, P.R.

Shearing, et al., Mass transfer in fibrous media with varying anisotropy for flow battery electrodes: Direct numerical simulations with 3D X-ray computed tomography, Chem. Eng. Sci. (2018). doi:10.1016/j.ces.2018.10.049.

Presents a fluid dynamics model for the determination of mass transfer coefficients in carbon felt from digitised electrode structures obtained from CT.

[28] D. Maggiolo, F. Zanini, F. Picano, A. Trovò, M. Guarnieri, Particle based method and X-ray computed tomography for pore-scale flow characterization in VRFB electrodes, Energy Storage Mater. 16 (2018) 91-96. doi:10.1016/j.ensm.2018.04.021.

[29] M.D.R. Kok, A. Khalifa, J.T. Gostick, Multiphysics simulation of the flow battery cathode: Cell architecture and electrode optimization, J. Electrochem. Soc. 163 (2016) A1408-A1419. doi:10.1149/2.1281607jes.

[30] M.R. Gerhardt, A.A. Wong, M.J. Aziz, The effect of interdigitated channel and land dimensions on flow cell performance, J. Electrochem. Soc. 165 (2018) A2625-A2643. doi:10.1149/2.0471811jes.

[31] Y. Li, M. Skyllas-Kazacos, J. Bao, A dynamic plug flow reactor model for a vanadium redox flow battery cell, J. Power Sources. 311 (2016) 57-67. doi:10.1016/j.jpowsour.2016.02.018.

[32] S. König, M.R. Suriyah, T. Leibfried, A plug flow reactor model of a vanadium redox flow battery considering the conductive current collectors, J. Power Sources. 360 (2017) 221-231. doi:10.1016/j.jpowsour.2017.05.085.

[33] A. Tang, J. Bao, M. Skyllas-Kazacos, Studies on pressure losses and flow rate optimization in vanadium redox flow battery, J. Power Sources. 248 (2014) 154-162.

[34] S. König, M.R. Suriyah, T. Leibfried, Innovative model-based flow rate optimization for vanadium redox flow batteries, J. Power Sources. 333 (2016) 134-144. doi:10.1016/j.jpowsour.2016.09.147.

[35] S. König, M.R. Suriyah, T. Leibfried, Validating and improving a zerodimensional stack voltage model of the vanadium redox flow battery, J. Power Sources. 378 (2018) 10-18. doi:10.1016/j.jpowsour.2017.12.014. 
[36] Z. Wei, A. Bhattarai, C. Zou, S. Meng, T.M. Lim, M. Skyllas-Kazacos, Realtime monitoring of capacity loss for vanadium redox flow battery, J. Power Sources. 390 (2018) 261-269. doi:10.1016/j.jpowsour.2018.04.063.

[37] B. Xiong, J. Zhao, Y. Su, Z. Wei, M. Skyllas-Kazacos, State of charge estimation of vanadium redox flow battery based on sliding mode observer and dynamic model including capacity fading factor, IEEE Trans. Sustain. Energy. 8 (2017) 1658-1667. doi:10.1109/TSTE.2017.2699288.

[38] A. Bhattacharjee, H. Samanta, N. Banerjee, H. Saha, Development and validation of a real time flow control integrated MPPT charger for solar PV applications of vanadium redox flow battery, Energy Convers. Manag. 171 (2018) 1449-1462. doi:10.1016/j.enconman.2018.06.088.

[39] H.F. A, K. Palanisamy, S. Padmanaban, U. Subramaniam, Intelligence-based battery management and economic analysis of an optimized dual-vanadium redox battery (VRB) for a wind-PV hybrid system, Energies. 11 (2018) 2785. doi:10.3390/en11102785.

[40] C. Minke, T. Turek, Materials, system designs and modelling approaches in techno-economic assessment of all-vanadium redox flow batteries - A review, J. Power Sources. 376 (2018) 66-81. doi:10.1016/j.jpowsour.2017.11.058.

[41] M. Resch, J. Bühler, B. Schachler, R. Kunert, A. Meier, A. Sumper, Technical and economic comparison of grid supportive vanadium redox flow batteries for primary control reserve and community electricity storage in Germany, Int. J. Energy Res. 43 (2019) 337-357. doi:10.1002/er.4269.

[42] M. Fisher, J. Apt, J.F. Whitacre, Can flow batteries scale in the behind-themeter commercial and industrial market? A techno-economic comparison of storage technologies in California, J. Power Sources. 420 (2019) 1-8. doi:10.1016/j.jpowsour.2019.02.051.

[43] C. Minke, U. Kunz, T. Turek, Techno-economic assessment of novel vanadium redox flow batteries with large-area cells, J. Power Sources. 361 (2017) 105114. doi:10.1016/j.jpowsour.2017.06.066.

[44] P. MacArtain, R. Byrne, N.J. Hewitt, Increased benefit of $\mathrm{ZnBr}$ flow battery with 33kWp PV system and smart tariff structure, Energy Procedia. 155 (2018) 514-523. doi:10.1016/j.egypro.2018.11.029.

[45] S. Weber, J.F. Peters, M. Baumann, M. Weil, Life cycle assessment of a vanadium redox flow battery, Environ. Sci. Technol. 52 (2018) 10864-10873. doi:10.1021/acs.est.8b02073. 
[46] - F. Moro, A. Trovò, S. Bortolin, D. Del Col, M. Guarnieri, An alternative lowloss stack topology for vanadium redox flow battery: Comparative assessment, J. Power Sources. 340 (2017) 229-241. doi:10.1016/j.jpowsour.2016.11.042.

Considers a multiphysics 3D numerical model at the level of stack arrays for the optimisation of a vanadium RFB.

[47] M. Yue, Q. Zheng, F. Xing, H. Zhang, X. Li, X. Ma, Flow field design and optimization of high power density vanadium flow batteries: A novel trapezoid flow battery, AIChE J. 64 (2018) 782-795. doi:10.1002/aic.15959.

[48] N. Pinjari, B. Kumar, A. Bhargav, P. Ruch, Effect of electrode properties on performance of miniaturized vanadium redox flow battery, in: 2017 16th IEEE Intersociety Conference on Thermal and Thermomechanical Phenomena in Electronic Systems (ITherm), IEEE, 2017: pp. 1040-1048. doi:10.1109/ITHERM.2017.7992603.

[49] J. Houser, A. Pezeshki, J.T. Clement, D. Aaron, M.M. Mench, Architecture for improved mass transport and system performance in redox flow batteries, J. Power Sources. 351 (2017) 96-105. doi:10.1016/j.jpowsour.2017.03.083.

[50] M. Al-Yasiri, J. Park, Study on channel geometry of all-vanadium redox flow batteries, J. Electrochem. Soc. 164 (2017) A1970-A1982. doi:10.1149/2.0861709jes.

[51] M. Yue, Z. Lv, Q. Zheng, X. Li, H. Zhang, Battery assembly optimization: Tailoring the electrode compression ratio based on the polarization analysis in vanadium flow batteries, Appl. Energy. 235 (2019) 495-508. doi:10.1016/j.apenergy.2018.10.136.

[52] - J. Xiong, M. Jing, A. Tang, X. Fan, J. Liu, C. Yan, Mechanical modelling and simulation analyses of stress distribution and material failure for vanadium redox flow battery, J. Energy Storage. 15 (2018) 133-144. doi:10.1016/j.est.2017.11.011.

Presents a mechanical 3D model of the compression of stack components.

[53] Q. Zheng, F. Xing, X. Li, G. Ning, H. Zhang, Flow field design and optimization based on the mass transport polarization regulation in a flowthrough type vanadium flow battery, J. Power Sources. 324 (2016) 402-411. doi:10.1016/j.jpowsour.2016.05.110. 
[54] M. MacDonald, R.M. Darling, Modeling flow distribution and pressure drop in redox flow batteries, AIChE J. 64 (2018) 3746-3755. doi:10.1002/aic.16330.

[55] S. Maurya, P.T. Nguyen, Y.S. Kim, Q. Kang, R. Mukundan, Effect of flow field geometry on operating current density, capacity and performance of vanadium redox flow battery, J. Power Sources. 404 (2018) 20-27. doi:10.1016/j.jpowsour.2018.09.093.

[56] • Q. Wang, Z.G. Qu, Z.Y. Jiang, W.W. Yang, Numerical study on vanadium redox flow battery performance with non-uniformly compressed electrode and serpentine flow field, Appl. Energy. 220 (2018) 106-116. doi:10.1016/j.apenergy.2018.03.058.

Provides a 3D numerical model of current and potential distribution in an interdigitated flow cell.

[57] Q. Wang, Z.G. Qu, Z.Y. Jiang, W.W. Yang, Experimental study on the performance of a vanadium redox flow battery with non-uniformly compressed carbon felt electrode, Appl. Energy. 213 (2018) 293-305. doi:10.1016/j.apenergy.2018.01.047.

[58] J. Houser, J. Clement, A. Pezeshki, M.M. Mench, Influence of architecture and material properties on vanadium redox flow battery performance, J. Power Sources. 302 (2016) 369-377. doi:10.1016/j.jpowsour.2015.09.095.

[59] Y.A. Gandomi, D.S. Aaron, T.A. Zawodzinski, M.M. Mench, In situ potential distribution measurement and validated model for all-vanadium redox flow battery, J. Electrochem. Soc. 163 (2016) A5188-A5201. doi:10.1149/2.0211601jes.

[60] C. Yin, S. Guo, H. Fang, J. Liu, Y. Li, H. Tang, Numerical and experimental studies of stack shunt current for vanadium redox flow battery, Appl. Energy. 151 (2015) 237-248. doi:10.1016/j.apenergy.2015.04.080.

[61] - R.M. Darling, H.-S. Shiau, A.Z. Weber, M.L. Perry, The relationship between shunt currents and edge corrosion in flow batteries, J. Electrochem. Soc. 164 (2017) E3081-E3091. doi:10.1149/2.0081711jes.

Illustrates the effect of shunt currents in cell stacks lacking manifold devices for decreasing the ionic conductivity among individual cells.

[62] J. Chen, T. Yan, E. Kizhnerman, H. Yin, M.-X. Zhang, D. Hui, Numerical analysis and optimization on shunt losses in a multi-stack VRFB system, in: 
2018 2nd IEEE Conference on Energy Internet and Energy System Integration (EI2), IEEE, Beijing, 2018. doi:10.1109/EI2.2018.8581653.

[63] H.-Y. Jung, G.-O. Moon, T. Sadhasivam, C.-S. Jin, W.-S. Park, H.-T. Kim, et al., Ionic transportation and chemical stability of high-endurance porous polyethylene separator for vanadium redox flow batteries, Solid State Ionics. 327 (2018) 110-116. doi:10.1016/j.ssi.2018.10.019.

[64] Y. Xing, L. Liu, C. Wang, N. Li, Side-chain-type anion exchange membranes for vanadium flow battery: properties and degradation mechanism, J. Mater. Chem. A. 6 (2018) 22778-22789. doi:10.1039/C8TA08813F.

[65] O. Nibel, S.M. Taylor, A. Pătru, E. Fabbri, L. Gubler, T.J. Schmidt, Performance of different carbon electrode materials: Insights into stability and degradation under real vanadium redox flow battery operating conditions, J. Electrochem. Soc. 164 (2017) A1608-A1615. doi:10.1149/2.1081707jes.

[66] I. Derr, D. Przyrembel, J. Schweer, A. Fetyan, J. Langner, J. Melke, et al., Electroless chemical aging of carbon felt electrodes for the all-vanadium redox flow battery (VRFB) investigated by Electrochemical Impedance and X-ray Photoelectron Spectroscopy, Electrochim. Acta. 246 (2017) 783-793. doi:10.1016/j.electacta.2017.06.050.

[67] C. Choi, S. Kim, R. Kim, J. Lee, J. Heo, H.-T. Kim, In-situ observation of the degradation of all-vanadium redox flow batteries with dynamic hydrogen reference electrode under real operation conditions, J. Ind. Eng. Chem. 70 (2019) 355-362. doi:10.1016/j.jiec.2018.10.036.

[68] J. Noack, N.V. Roznyatovskaya, N. Gurieff, C. Menictas, M. Skyllas-Kazacos, Current Development Trends and Challenges for Redox-Flow Batteries, in: Modval 2018 conference, Aarau, Switzerland, 2018. doi:10.13140/RG.2.2.36107.39205.

[69] L.F. Arenas, R.P. Boardman, C. Ponce de León, F.C. Walsh, X-ray computed micro-tomography of reticulated vitreous carbon, Carbon. 135 (2018) 85-94. doi:10.1016/j.carbon.2018.03.088.

[70] X.L. Zhou, T.S. Zhao, L. An, Y.K. Zeng, X.B. Zhu, Performance of a vanadium redox flow battery with a VANADion membrane, Appl. Energy. 180 (2016) 353-359. doi:10.1016/j.apenergy.2016.08.001.

[71] Y. Zhang, X. Zhou, R. Xue, Q. Yu, F. Jiang, Y. Zhong, Proton exchange membranes with ultra-low vanadium ions permeability improved by sulfated 
zirconia for all vanadium redox flow battery, Int. J. Hydrogen Energy. 44 (2019) 5997-6006. doi:10.1016/j.ijhydene.2019.01.043.

[72] S. Kim, E. Thomsen, G. Xia, Z. Nie, J. Bao, K. Recknagle, et al., 1 kW/1 kWh advanced vanadium redox flow battery utilizing mixed acid electrolytes, J. Power Sources. 237 (2013) 300-309. doi:10.1016/j.jpowsour.2013.02.045.

[73] D. Reed, E. Thomsen, Bin Li, W. Wang, Z. Nie, B. Koeppel, et al., Stack developments in a $\mathrm{kW}$ class all vanadium mixed acid redox flow battery at the Pacific Northwest National Laboratory, J. Electrochem. Soc. 163 (2016) A5211-A5219. doi:10.1149/2.0281601jes.

[74] M. Guarnieri, A. Trovò, A. D'Anzi, P. Alotto, Developing vanadium redox flow technology on a 9-kW 26-kWh industrial scale test facility: Design review and early experiments, Appl. Energy. 230 (2018) 1425-1434. doi:10.1016/j.apenergy.2018.09.021.

[75] - D. Bryans, V. Amstutz, H. Girault, L. Berlouis, Characterisation of a 200 kW/400 kWh vanadium redox flow battery, Batteries. 4 (2018) 54. doi: $10.3390 /$ batteries 4040054 .

Demonstrates the practical characterization of energy efficiency in a utility-scale RFB system.

[76] L. Kopietz, P. Schwerdt, J. Girschik, J. Burfeind, A. Grevé, C. Doetsch, Extralarge bipolar plates for redox flow batteries, in: Procedings of the The International Flow Battery Forum 2017, Manchester, UK, 2017: pp. 46-47.

[77] - M. Averbukh, A. Pozin, S. Sukoriansky, Electrolyte pumping optimization in already manufactured vanadium redox battery based on experimentally determined electrical and hydrodynamic losses, J. Energy Eng. (2016) 04016050. doi:10.1061/(ASCE)EY.1943-7897.0000398.

Reports experimental data for the pressure drop characteristics of carbon felt for the viscosity of vanadium electrolytes.

[78] T. Davies, J. Tummino, High-performance vanadium redox flow batteries with graphite felt electrodes, J. Carbon Research. 4 (2018) 8-17. doi:10.3390/c4010008.

[79] Q. Ye, J. Hu, P. Cheng, Z. Ma, Design trade-offs among shunt current, pumping loss and compactness in the piping system of a multi-stack vanadium flow battery, J. Power Sources. 296 (2015) 352-364.

doi:10.1016/j.jpowsour.2015.06.138. 
[80] V.K. Arun Shankar, S. Umashankar, S. Paramasivam, N. Hanigovszki, A comprehensive review on energy efficiency enhancement initiatives in centrifugal pumping system, Appl. Energy. 181 (2016) 495-513.

[81] H. Tanaka, Y. Miyafuji, J. Fukushima, T. Tayama, T. Sugita, M. Takezawa, et al., Visualization of flow patterns in a cell of redox flow battery by infrared thermography, J. Energy Storage. 19 (2018) 67-72.

doi:10.1016/j.est.2018.07.009.

[82] Y.A. Gandomi, J. Houser, D. Aaron, M.M. Mench, Passive mitigation of capacity decay in vanadium redox flow batteries through asymmetric cell configuration, ECS Meet. Abstr. MA2017-01 (2017) 152.

[83] K. Schafner, M. Becker, T. Turek, Capacity balancing for vanadium redox flow batteries through electrolyte overflow, J. Appl. Electrochem. 48 (2018) 639649. doi:10.1007/s10800-018-1187-1.

[84] A. Bhattarai, N. Wai, R. Schweiss, A. Whitehead, G.G. Scherer, P.C. Ghimire, et al., Study of flow behavior in all-vanadium redox flow battery using spatially resolved voltage distribution, J. Power Sources. 360 (2017) 443-452. doi:10.1016/j.jpowsour.2017.06.039.

[85] L. Cao, M. Skyllas-Kazacos, C. Menictas, J. Noack, A review of electrolyte additives and impurities in vanadium redox flow batteries, J. Energy Chem. 27 (2018) 1269-1291. doi:10.1016/j.jechem.2018.04.007.

[86] C.S. Sevov, D.P. Hickey, M.E. Cook, S.G. Robinson, S. Barnett, S.D. Minteer, et al., Physical organic approach to persistent, cyclable, low-potential electrolytes for flow battery applications, J. Am. Chem. Soc. 139 (2017) 2924 2927. doi:10.1021/jacs.7b00147.

[87] Z. Li, Y.-C. Lu, Redox flow batteries: want more electrons? Go organic! Chem. 4 (2018) 2020-2021. doi:10.1016/j.chempr.2018.08.032.

[88] Y. Ding, C. Zhang, L. Zhang, Y. Zhou, G. Yu, Molecular engineering of organic electroactive materials for redox flow batteries, Chem. Soc. Rev. 47 (2018) 69-103. doi:10.1039/C7CS00569E.

[89] L. Cheng, R.S. Assary, X. Qu, A. Jain, S.P. Ong, N.N. Rajput, et al., Accelerating electrolyte discovery for energy storage with high-throughput screening, J. Phys. Chem. Lett. 6 (2015) 283-291. doi:10.1021/jz502319n. 
[90] •• P. Leung, A.A. Shah, L. Sanz, C. Flox, J.R. Morante, Q. Xu, et al., Recent developments in organic redox flow batteries: A critical review, J. Power Sources. 360 (2017) 243-283. doi:10.1016/j.jpowsour.2017.05.057.

Presents a recent, critical summary of activity in organic and non-aqueous systems and identifies areas needing further research.

[91] C. Zhang, L. Zhang, Y. Ding, X. Guo, G. Yu, Eutectic electrolytes for highenergy-density redox flow batteries, ACS Energy Lett. 3 (2018) 2875-2883. doi:10.1021/acsenergylett.8b01899.

[92] E.S. Beh, D. De Porcellinis, R.L. Gracia, K.T. Xia, R.G. Gordon, M.J. Aziz, A neutral $\mathrm{pH}$ aqueous organic-organometallic redox flow battery with extremely high capacity retention, ACS Energy Lett. 2 (2017) 639-644.

[93] B. Hu, C. DeBruler, Z. Rhodes, T.L. Liu, Long-cycling aqueous organic redox flow battery (AORFB) toward sustainable and safe energy storage, J. Am. Chem. Soc. 139 (2017) 1207-1214. doi:10.1021/jacs.6b10984.

[94] I.L. Escalante-García, J.S. Wainright, L.T. Thompson, R.F. Savinell, Performance of a non-aqueous vanadium acetylacetonate prototype redox flow battery: Examination of separators and capacity decay, J. Electrochem. Soc. 162 (2015) A363-A372. doi:10.1149/2.0471503jes.

[95] J.D. Saraidaridis, C.W. Monroe, Nonaqueous vanadium disproportionation flow batteries with porous separators cycle stably and tolerate high current density, J. Power Sources. 412 (2019) 384-390. doi:10.1016/j.jpowsour.2018.11.058.

[96] - M.J. Watt-Smith, P. Ridley, R.G.A. Wills, A.A. Shah, F.C. Walsh, The importance of key operational variables and electrolyte monitoring to the performance of an all vanadium redox flow battery, J. Chem. Technol. Biotechnol. 88 (2012) 126-138. doi:10.1002/jctb.3870.

Considers monitoring of electrolyte redox potential and the effect of operational conditions (current density and flow velocity) plus a validated chargedischarge model over numerous cycles.

[97] I. Derr, M. Bruns, J. Langner, A. Fetyan, J. Melke, C. Roth, Degradation of allvanadium redox flow batteries (VRFB) investigated by electrochemical impedance and X-ray photoelectron spectroscopy: Part 2 electrochemical degradation. J Power Sources. 325 (2016) 351-359. http://dx.doi.org/10.1016/j.jpowsour.2016.06.040 


\section{Figure Captions}

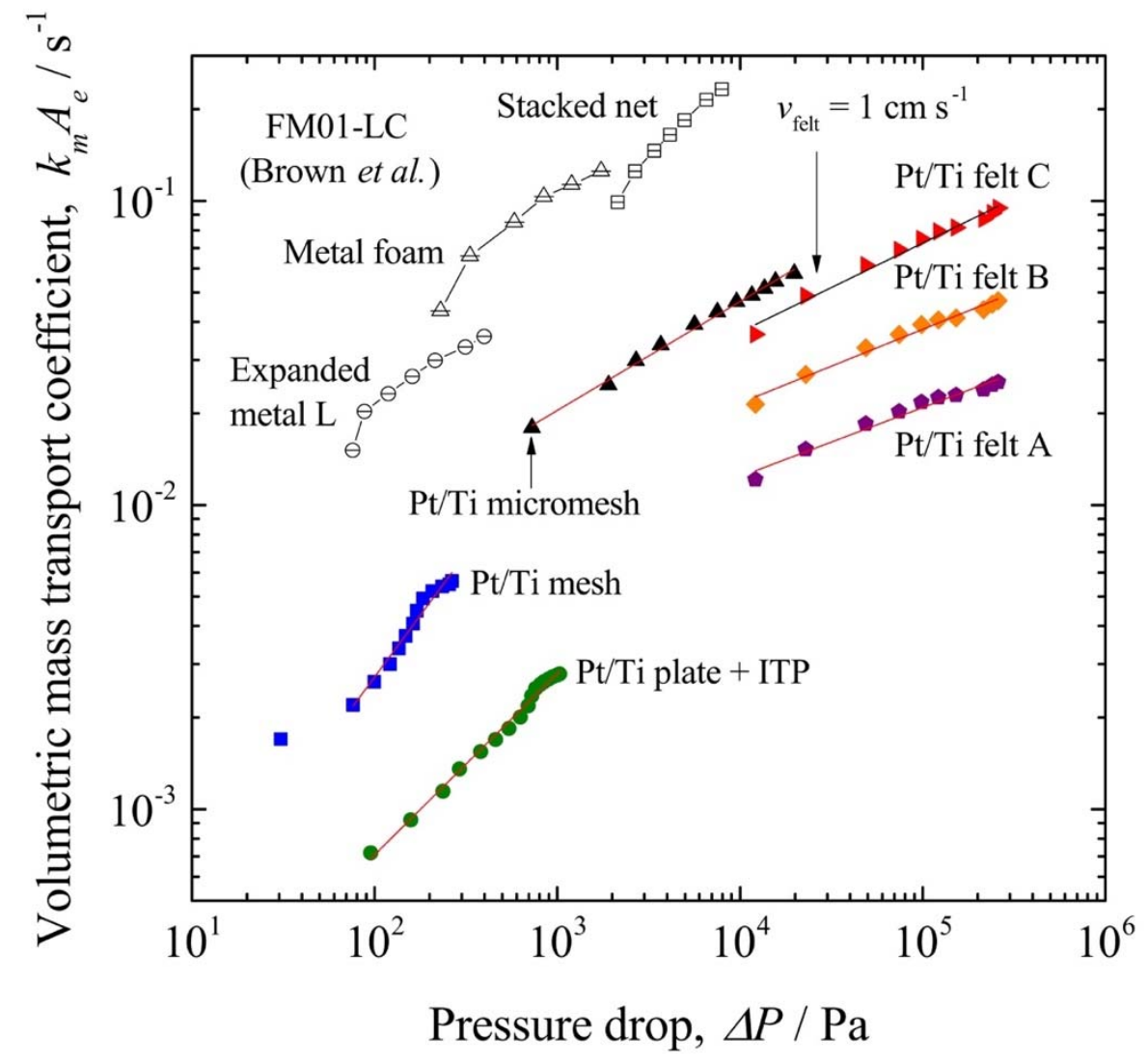

Figure 1. The normalised performance of two cell designs under full mass transfer reaction control having different porous electrodes and electrolytes. The product $k_{m} A_{e}$ is plotted as a function of pressure drop due to electrolyte flow rate. Pt/Ti electrodes correspond to a laboratory cerium-based RFB and others to a FM01-LC electrolyser [12]. Reprinted with permission from Arenas et al. [14], Pressure drop through platinised titanium porous electrodes for cerium-based redox flow batteries, AIChE Journal 64(3):1135-46. Copyright (2017) John Wiley and Sons. 

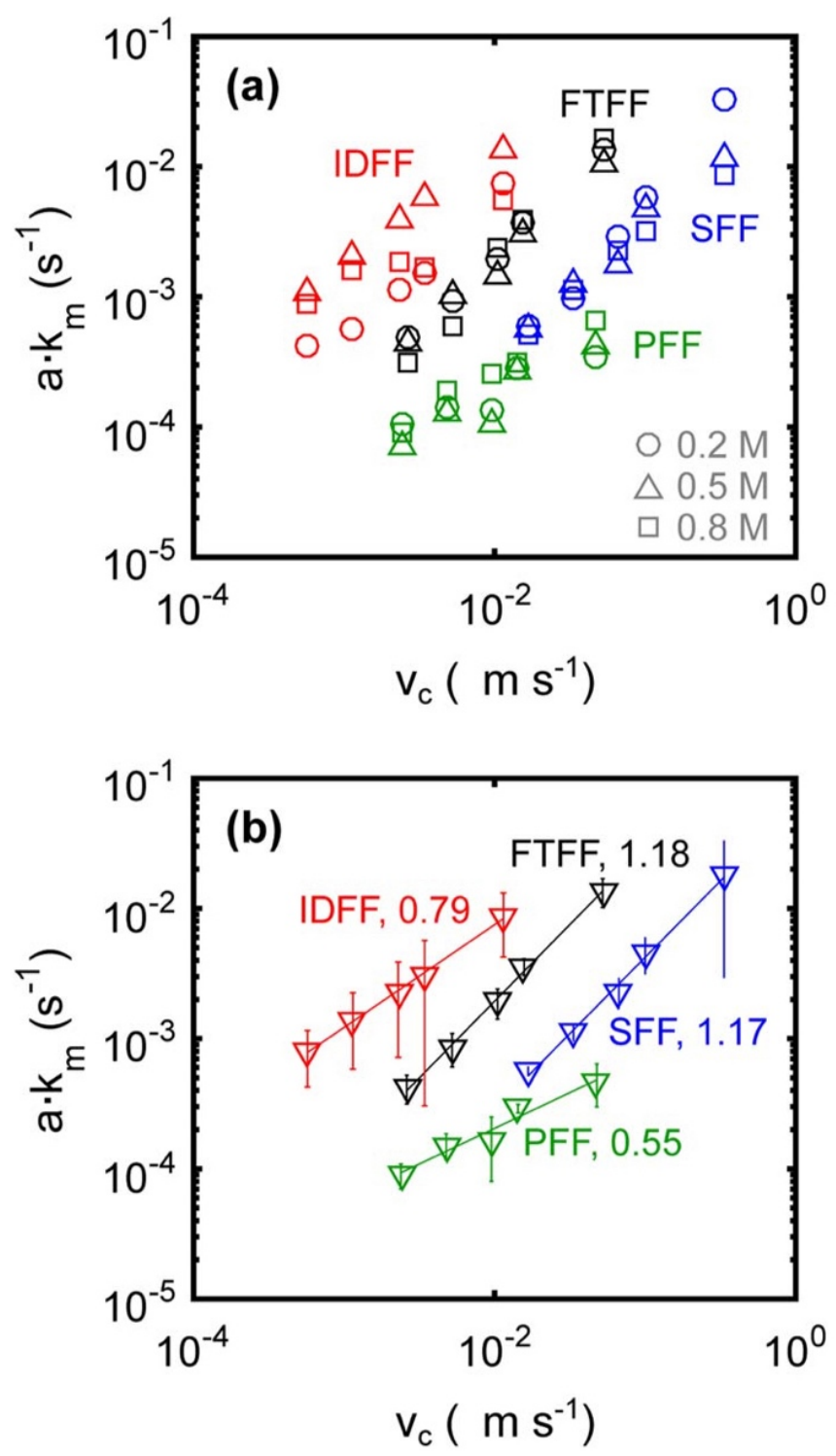

Figure 2. The performance of different flow field designs in a $2.55 \mathrm{~cm}^{2}$ symmetrical cell for the $\mathrm{Fe}^{2+} / \mathrm{Fe}^{3+}$ redox couple. a) $k_{m} A e$ is plotted as a function of characteristic flow velocity (related to flow field dimensions) for different concentrations: $0.2 \mathrm{~mol} \mathrm{dm}^{-3}$ (०), $0.5 \mathrm{~mol} \mathrm{dm}^{-3}(\Delta)$, and $0.8 \mathrm{~mol} \mathrm{dm}^{-3}(\square)$. b) Mean $k m A e$ values fitted to linear relationships along their slope values. Flow field types: parallel (PFF), serpentine (SFF), interdigitated (IDFF), and flow through (FTFF). Adapted with permission from Milshtein et al. [21], Quantifying mass transfer rates in redox flow batteries, Journal of the Electrochemical Society 164(11):E3265-75. Open access licence (2017) CC BY 4.0 . 


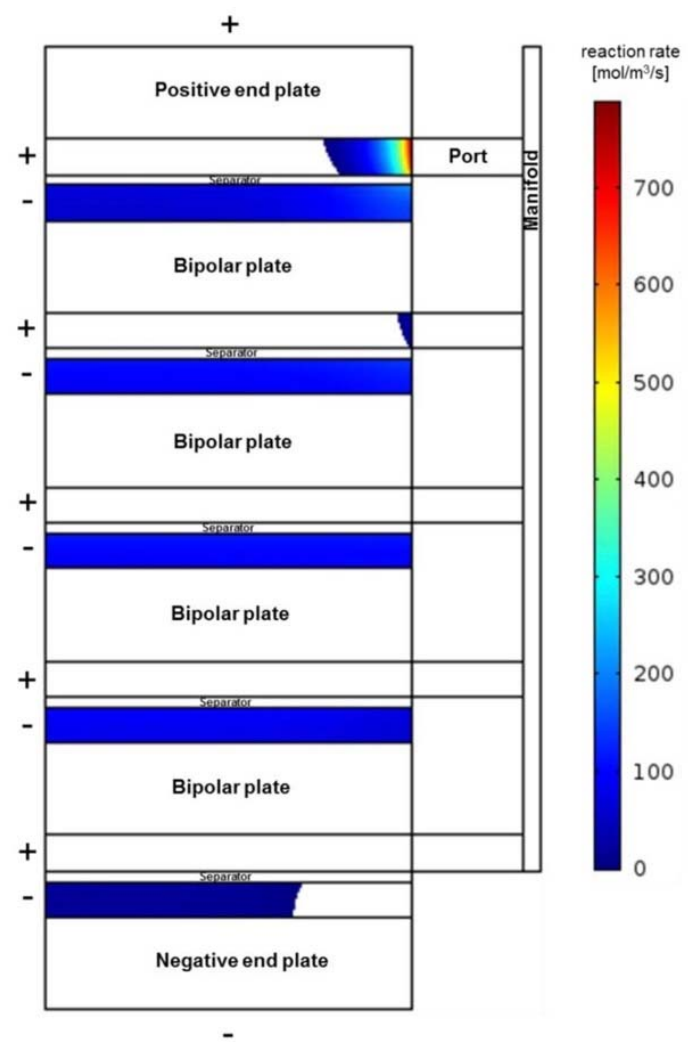

(a) Oxidation reactions

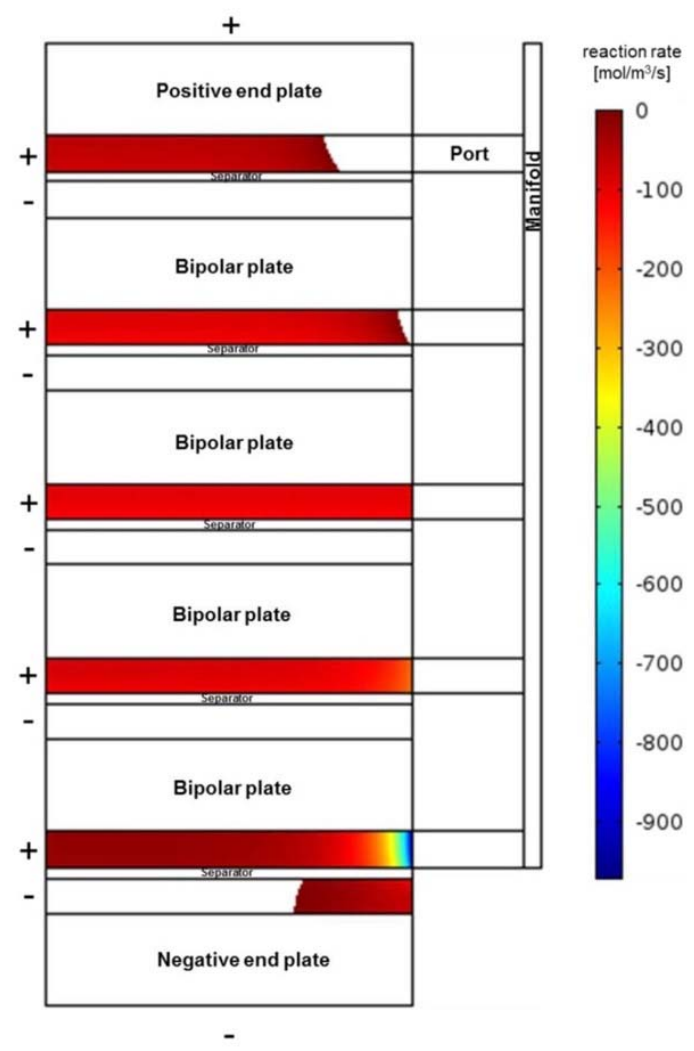

(b) Reduction reactions

Figure 3. Undesirable reaction reversal near electrolyte inlets in a bipolar cell stack deliberately lacking measures against shunt currents. Electrode zones where oxidation and reduction of vanadium ions take place are indicated by their simulated local reaction rate. For clarity, only the common manifold feeding the positive electrodes with electrolyte is shown. Reprinted with permission from Darling et al. [61], The relationship between shunt currents and edge corrosion in flow batteries, Journal of the Electrochemical Society 164(11):E3081-91. Open access (2017) CC BY 4.0 licence. 

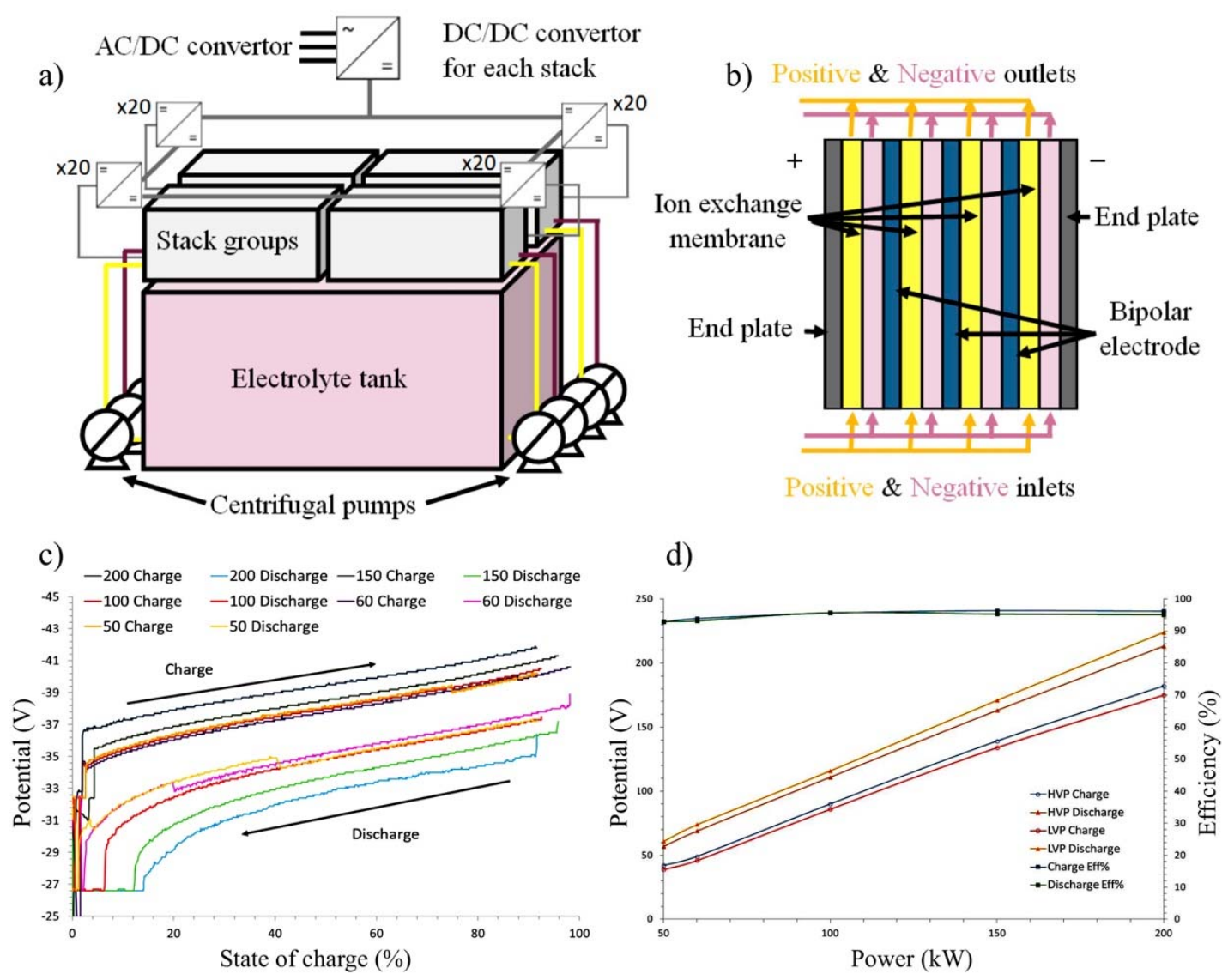

d)

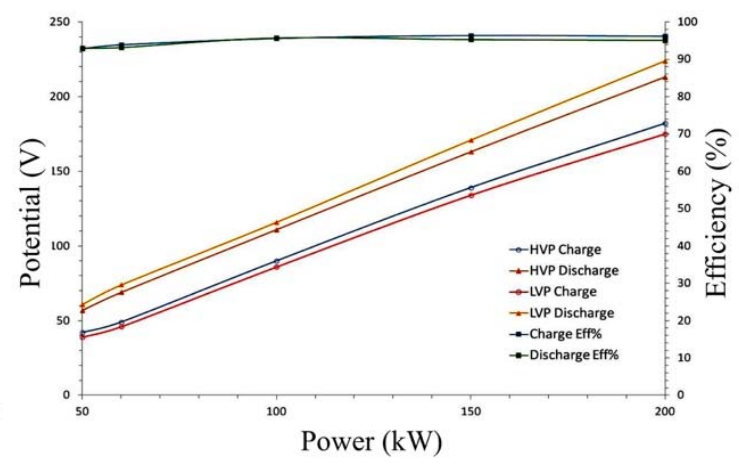

Figure 4. a) A four-stack $200 \mathrm{~kW} / 400 \mathrm{~kW}$ h vanadium RFB along pump and power conditioner. b) Arrangement of bipolar electrodes and electrolyte flow. c) Total stack potential over a range of constant power charge-discharge values. d) DC/DC convertor potential losses and efficiency at 'high voltage' (HVP) and 'low voltage' (LVP) modes. Adapted with permission from Bryans et al. [75], Characterisation of a $200 \mathrm{~kW} / 400 \mathrm{~kW}$ h vanadium redox flow battery, Batteries 4:54. Open access (2018) CC BY 4.0 licence. 